\title{
Development of an environmentally friendly formulation of silk fibroin associated with fatty acid from Astrocaryum murumuru Mart. fat, effective against larvae of the Aedes aegypti vector
}

Victor H. S. Marinho

UNIFAP: Universidade Federal do Amapa

Fernando B. Neves

UNIFAP: Universidade Federal do Amapa

David E. Q. Jimenez

UNIFAP: Universidade Federal do Amapa

Fabio R. Oliveira

UNIFAP: Universidade Federal do Amapa

Abrahão Victor T. L. T. Santos

UNIFAP: Universidade Federal do Amapa

Ricardo M. A. Ferreira

UNIFAP: Universidade Federal do Amapa

Raimundo N. P. Souto

UNIFAP: Universidade Federal do Amapa

José C. T. Carvalho

UNIFAP: Universidade Federal do Amapa

Sérgio A. Yoshioka

USP: Universidade de Sao Paulo

Irlon Maciel Ferreira ( $\square$ irlon.ferreira@gmail.com )

UNIFAP https://orcid.org/0000-0002-4517-0105

\section{Research Article}

Keywords: Emulsion, Ester, Silk fibroin, Larvicidal activity, Biomaterial, Biopesticide

Posted Date: June 11th, 2021

DOl: https://doi.org/10.21203/rs.3.rs-570302/v1

License: (c) (1) This work is licensed under a Creative Commons Attribution 4.0 International License.

Read Full License 
Page $2 / 22$ 


\section{Abstract}

The Aedes aegypti mosquito is a vector of several diseases, such as dengue, malaria and the Zika virus. Synthetic insecticides such as chlorpyrifos and chlorothalonil have been used for plague control, despite causing damage to the environment and to humans. It is therefore important to study natural active compounds with a low environmental impact. The present paper developed an environmentally friendly formulation of silk fibroin (SF) associated with fatty acid esters [ethyl (FAEE-SF), propyl (FAPE-SF) and butyl (FABE-SF)] from Astrocaryum murumuru Mart. fat, which was effective against Aedes aegypti 3th instar larvae. The FABE-SF nanoemulsion induced a higher mortality rate in the larvae of the $A$. aegypti after $48 \mathrm{~h}\left(\mathrm{LC}_{50}=18.92 \mu \mathrm{g} / \mathrm{mL}\right)$. The stabilities of the nanoemulsions were monitored for 21 days, and FABE-SF exhibited greater stability throughout the monitored period, with average particle, zeta and PDI values of around $217 \pm 0.85 \mathrm{~nm},-25.6 \pm 3.24 \mathrm{mV}$ and $0.338 \pm 0.01$, respectively. This paper reported the first effective action of fatty acid esters from $A$. murumuru Mart. associated with silk fibroin against $A$. aegypti. The FABE-SF solution also had a low hemolytic index, suggesting that treatment may be safe for animal and human use.

\section{Introduction}

The effective and sustainable control of mosquito populations and vectors of diseases is currently a challenge (Baldacchino et al. 2015; Benelli and Mehlhorn 2016). For many years, the control of mosquito populations has involved the preferential use of various synthetic insecticides, such as organochlorines, organophosphates and pyrethroids (Rodrigues et al. 2019). However, the indiscriminate and frequent use of such substances has caused selected populations of mosquitoes to become more resistant, as well as resulting in environmental pollution caused by their non-selective inhibitory enzymatic action (Gilliom and Hamilton 2006), that sets humans and other non-target organisms at risk (Sarwar et al. 2009). An alternative is the search for an effective low-cost insecticide, with lower environmental risk (Baldacchino et al. 2015; Benelli and Mehlhorn 2016).

In this context, there is growing demand for the use of natural products such as bioinsecticides, as plant extracts or fractions thereof contain a diversity of bioactive compounds, such as triglycerides, free fatty acids, fatty esters, alkanolamides, terpenes, and flavonoids, which in some cases act as acetylcholinesterase inhibitors (Sharma et al. 2009). Thus, the fat extracted from the fruits of Astrocaryum murumuru Mart represent a favorable alternative for hypothetically larvicidal biocomposites. A. murumuru fat is easily obtained, as the species of plant is widely distributed around the Amazon estuary (Bezerra 2012). Its natural oil is widely used as a raw material for the manufacture of cosmetics and in the food industry, such as in the production of margarine (Bezerra 2012), due to its favorable composition of saturated fatty acids such as palmitic and stearic acid (Erdemoglu and Kusmenoglu 2003; Korul'kina et al. 2004).

The larvicidal, insecticidal, and repellent action of fatty acid against mosquitoes has been widely reported in literature (Suarez et al. 2007), (Bosch et al. 2000; Perumalsamy et al. 2015), although there are few 
studies about the effects of natural products on insects, when used as larvicidal agents (Sharma et al. 2011).

Emulsification methods using co-polymers and proteins have become a viable alternative for enhancing the dispersion of essential or fixed oils in aqueous vehicles, as mosquitoes and other disease vectors need an aqueous environment to develop their life cycle (Echeverría and Albuquerque, 2019). Emulsions are formed and stabilized by surfactants or by amphiphilic polymers, which aim to reduce interfacial tension when adsorbed at the oil/water interface (Kaci et al. 2017; Sarquis et al. 2020). In comparison, silk fibroin is as an alternative to the various types of surfactants used in the formulation of emulsions, due to its low production cost, low cellular and environmental toxicity and high biodegradability, as well as being a biomaterial based on proteins (Ferreira et al. 2017a).

During the last decade, nanotechnology has presented a wide scope of applications in different areas such as medicine, electronics, catalysis and agriculture (Pavoni et al. 2019). With its advent, nanopesticides or nanoformulations that are thin films or encapsulation of the active ingredient of the pesticide in nanostructures have emerged, the main advantage of these nanostructures is the slow and controlled release of their active principles (Bilia et al. 2014). These make them environmentally safe and non-hazardous compared to chemical pesticides (Mehlhorn 2016).

In this context, the researchers have been developing different types of nanopesticides, such as nanoencapsulated formulations, nanoemulsions, nanogels, nanospheres, among others (Kah and Hofmann, 2014). In this way, nanoparticles can help in the production of new pesticides, insecticides and repellents and nanoemulsions can guarantee an efficient and controlled release of the active ingredients (Athanassiou et al. 2018). With this, the nanotechnology can revolutionize insect management, as it can provide innovative tools for the controlled and safe delivery of pesticides (Rai and Ingle, 2012).

Silk fibroin is a natural polymer produced by various insects, and is therefore subject to great diversity in its sequence, structure, and properties (Zhang et al. 2007). The study of silks has been carried out from the cocoon of the domesticated silkworm Bombyx mori and the Nephila clavipes spider (Noufi 1995). Silk fibroin is a natural amphiphilic block of hydrophobic and hydrophilic co-polymers that collectively mix, giving silk fibroin flexibility and robustness (Tanaka et al. 1999; Zhang et al. 2007). Due to its excellent mechanical properties, high biocompatibility, biodegradability, and low cost (Pham and Tiyaboonchai 2020), silk fibroin is used in tissue engineering, and in the delivery system of bioactive compounds, such as drugs, peptides and proteins, among others (Kundu et al. 2010; Koh et al. 2015), in addition to a variety of biomaterials, such as nanoparticles, nanospheres, hydrogels and films (Cheng et al. 2017).

Our research group has been investigating the action of emulsions prepared with silk protein and larvicidal actives. Recently, our Group has developing biopesticides based on the use of silk fibroin as a vehicle co-polymeric. Araújo (Araújo et al. 2020) evaluated the larvicidal action of the hydroethanolic, methanolic, and hexane extracts of Acmella oleracea leaves solubilized in silk fibroin (2\%), and Sarquis (Sarquis et al. 2020), that reported the use of free fatty acids from Carapa guianensis Aubl oil associated 
with silk fibroin, and its activity against $A$. aegpyti larvae, and found excellent $\mathrm{LC}_{50}$ results after $48 \mathrm{~h}$ of $16.7 \mu \mathrm{g} \cdot \mathrm{mL}^{-1}$.

Therefore, continuing the study of silk protein as a vehicle for active larvicides, the present study aimed to evaluate the preparation of potentially sustainable, stable, and low-cost larvicidal emulsions containing fatty esters from $A$. murumuru fat, associated with silk fibroin.

\section{Material And Methods}

\subsection{Reagents and solvents}

The fat of Astrocaryum murumuru Mart. was purchased from Aspacs (Amazonas, Brazil). Ethanol (99\%) was purchased from Solven (São Paulo, Brazil), isopropanol and butanol were purchased from Quimex. The solvents $n$-hexane (98.5\%) and ethyl acetate (98\%), used in the purification of the esters by column chromatography, were obtained from Synth (São Paulo, Brazil) and Amano AK Lipase from Pseudomonas fluorescens (20.000 U/g) was purchased from Sigma-Aldrich (São Paulo, Brazil).

\subsection{Synthesis of ethyl, isopropyl and butyl esters of $A$. murumuru Mart. fat catalyzed by Amano AK lipase from Pseudomonas fluorescens}

The enzymatic transesterification of fat was performed separately for ethyl, isopropyl and $n$-butyl alcohols to generate the respective esters (FAEE, FAPE and FABE), as described by Ferreira with some modifications (Ferreira et al. 2017b).

Transesterification was performed in a $50 \mathrm{~mL}$ reaction flask containing $1.0 \mathrm{~g}$ of fat, $3 \mathrm{~mL}$ of respective alcohol and $0.1 \mathrm{~g} \mathrm{(10 \% )} \mathrm{of} \mathrm{Lipase} \mathrm{from} \mathrm{Pseudomonas} \mathrm{fluorescens.} \mathrm{The} \mathrm{reaction} \mathrm{mixtures} \mathrm{were}$ magnetically stirred for $24 \mathrm{~h}$ at room temperature. Afterwards, the reaction solutions were filtered, the organic phases were dried with anhydrous sodium sulfate and filtered, and the solvents were removed by vacuum under reduced pressure. The products were purified by silica gel column chromatography, with the mobile phase being a mixture of $n$-hexane and ethyl acetate (9:1). The isolated products were characterized by their spectroscopic data (GC-MS and FTIR).

\subsection{Gas chromatography-mass espectrometry (GC-MS)}

The samples (FAEE, FAPE and FABE) were analyzed by gas chromatography mass spectrometry. The gas chromatography-mass spectrometry (GC-MS) analyses were performed in a Shimadzu GC2010 with a mass selective detector (Shimadzu MS2010plus) in electron ionization mode (El, $70 \mathrm{eV}$ ). The GC-MS (equipped with a $30 \mathrm{~m} \times 0.25 \mathrm{~mm} \times 0.25 \mu \mathrm{m}$ RTX- $5 \mathrm{MS}$ column) conditions were: the oven temperature started at $130^{\circ} \mathrm{C}$ and was kept for $2 \mathrm{~min}$, increased to $290^{\circ} \mathrm{C}$ at $5^{\circ} \mathrm{C} \mathrm{min}^{-1}$, maintained for $2 \mathrm{~min}$. The total analysis time was $36 \mathrm{~min}$. The injector and detector temperature was maintained at $210^{\circ} \mathrm{C} ; 1 \mu \mathrm{L}$ was 
injected with 1:15 split and helium was used as the carrier gas at a $1.0 \mathrm{~mL} \mathrm{~min} \mathrm{~m}^{-1}$ flow rate. The ions were monitored from 3 to $36 \mathrm{~min}$ in the $\mathrm{m} / \mathrm{z}$ 40-500. The components present in the samples were identified through comparison of spectral data with those in the Wiley library.

\subsection{Infrared spectroscopy analysis}

A Fourier transform infrared spectrophotometer (Shimadzu FTIR IRTracer-100) recorded the spectra of FAT ( $A$. murumuru), FAEE, FAPE and FABE using a potassium bromide beam splitter. The KBr pellet method was employed, and the background spectrum was collected. The range was set from 400 to 4000 $\mathrm{cm}^{-1}$ with $16-\mathrm{cm}^{-1}$ resolution.

\subsection{Preparation of the silk fibroin solution}

The silk fibroin solution was prepared based on the method developed by Ferreira (Ferreira et al., 2014). Silkworm cocoon ( $3.0 \mathrm{~g}$, from Bratac, Brazil) were degummed in boiling a $(2 \%, \mathrm{w} / \mathrm{v}) \mathrm{Na}_{2} \mathrm{CO}_{3}$ solution for $30 \mathrm{~min}$. The resultant fibers were filtrated and washed with distilled water $(3 \times 500 \mathrm{~mL})$. Subsequently, silk fiber were dissolved in a ternary solution $(50 \mathrm{~mL})$ of $\mathrm{H}_{2} \mathrm{O}: \mathrm{EtOH}: \mathrm{CaCl}_{2}\left(8: 2: 1\right.$ molar proportions) at $30^{\circ} \mathrm{C}$ for $4 \mathrm{~h}$. This mixture was then dialyzed (cellulose tube with an exclusion limit of $16 \mathrm{kDa}$, from Viskase, Brazil) for 3 days at room temperature, and water changed every 24 hours. The fibroin solution was centrifuged (6000 rpm for $10 \mathrm{~min}$ ) to remove impurities and larger particles. The concentration of the silk fibroin solution was adjusted to $2 \%(\mathrm{w} / \mathrm{w})$.

\subsection{Preparation of ester/silk fibroin emulsions}

The emulsions were produced using a spontaneous emulsification process that occurs when an aqueous phase and an organic phase are mixed. In summary, deionized water was added to a mixture of esters (FAEE, FAPE or FABE) and the silk fibroin solution (2\%). The $10 \mathrm{~mL}$ solution contained $94 \%$ silk fibroin solution (2\%), $1 \%$ active compounds and $5 \%$ of a mixture of ethanol and isopropanol (1:1). The emulsions were prepared according to Sarquis et al. (2020), with slight modifications.

Initially, a mixture of ethanol and isopropanol was added to the esters (FAEE, FAPE or FABE) under constant magnetic agitation (300 rpm) for $30 \mathrm{~min}$. Next, the aqueous phase containing silk fibroin solution was added with continuous agitation for 5 min in vortex.

Emulsions were stored under $4^{\circ} \mathrm{C}$ and evaluated from 1 to 21 days following preparation. The droplet size, polydispersity index and zeta potential of the emulsions were determined using a ZS zetasizer (Malvern, United Kingdom). Each sample was diluted with distilled water (1:10) for analysis. Measurements were made in triplicate. The average droplet size was expressed as mean diameter. All analyzes were performed at $25^{\circ} \mathrm{C}$.

\subsection{Larvicidal activity}

Esters combined with silk fibroin emulsions (FAEE-SF, FAPE-SF and FABE-SF) were prepared in different concentrations $\left(7.5,15,25,50\right.$ and $\left.75 \mu \mathrm{g} \cdot \mathrm{mL}^{-1}\right)$ for the larvicidal tests in $A$. aegypti. Five replicates with 
10 larvae each were performed. The negative control consisted of the silk fibroin solution without the asset, and dichlorvos solution ( $\left.6.25 \mathrm{ng} \cdot \mathrm{mL}^{-1}\right)$ was used as the positive control. The larval mortality rate was determined after $24 \mathrm{~h}$ and $48 \mathrm{~h}$ of incubation at a temperature of $25^{\circ} \mathrm{C}$ and a humidity of $75 \%$. The larvae were considered dead when they did not respond to any stimulus or did not move on the surface of the solution, in contrast to those observed in the control. The bioassay was conducted according to WHO guidelines (2005).

\subsection{Morphological analysis on larvae}

After treatment, larvae were fixed in $10 \%$ formalin. Their external morphology was then analyzed under an optical microscope (with $6 \mathrm{~V} \mathrm{DC}$ and $20 \mathrm{~W}$ output) and was photographed using a digital camera (MDCE SC USB 2.0) with the Scopelm age software 9.0 package.

\subsection{Hemolysis assay}

Potential membrane injuries were evaluated according to the hemolysis assay protocol (Kang et al. 2009). Mouse blood was collected and centrifuged (3000 rpm/5 min), and erythrocytes were washed and suspended at $2 \%$ with $0.85 \%$ saline solutions. The FAEB-SF and negative control was used at final concentrations of $5,10,25,50$ and $75 \mu \mathrm{g} \cdot \mathrm{mL}^{-1}$, and the cells were incubated for $1 \mathrm{~h}$ at room temperature. $0.1 \%$ Triton X-100 was used as the positive control. Samples were centrifuged (3000 rpm/5 min), and the hemoglobin released was measured at $450 \mathrm{~nm}$. The results were expressed in \% of hemolysis compared to the positive control.

\subsection{Statistical analysis}

Probit analysis was performed with a $95 \%$ confidence interval to determine the Lethal concentrations $\left(\mathrm{LC}_{50}\right.$ and $\left.\mathrm{LC}_{90}\right)$ and Chi-square using software Statgraphics Centurion XV version 15.2.11 (Statpoint Technologies, Inc., Warrenton, VA). If the control mortality of the treated groups was between $5 \%$ and $20 \%$, the analysis was corrected in accordance with the WHO guidelines (2005) formula mortality $(\%)=X-Y$ / $X \times 100$, where $X=$ percentage survival in the untreated control group and $Y=$ percentage survival in the treated sample. Results of hemolysis test were expressed as mean \pm standard deviation (SD) using GraphPad Prism 8.0 software. Normality and homogeneity of variances were verified with KolmogorovSmirnov and Levene's tests, respectively. Comparisons among the Triton X-100, Murumuru fat and FABESF groups results were performed using one-way Analysis of variance (ANOVA) and a Tukey post-test. The minimum significance level was set at $p<0.05$ in all cases.

\section{Results And Discussion}

The transesterification reaction of $A$. murumuru with ethanol, isopropanol and $n$-butanol using Amano AK lipase from $P$. fluorescens provided a fatty acid ethyl ester (FAEE) percentage of $78.4 \%$, a fatty acid propyl ester (FAPE) percentage of $75.1 \%$ and a fatty acid butyl ester (FABE) percentage of $63.5 \%$, after purification in a chromatographic column with silica gel. 
The gas chromatographic analysis of FAEE from A. murumuru showed a composition formed of saturated, monounsaturated and polyunsaturated fatty acids (Table 1). However, A. murumuru fat from the present study identified a highest saturated fatty acid percentage of $95.5 \%$, with the predominant presence of lauric acid (C12:0) and myristic acid (C14:00), at 53.5\% and 25.8\% respectively. Other saturated fatty acids, such as palmitic (C16:0), stearic (C18:0), capric (C10:0) and caprylic (C14:00) acids, were also present in $A$. murumuru fat, in smaller proportions (Table 1). From the unsaturated fatty acid, oleic (C18:1) and linoleic (C18:2) acid were identified, at 3.8\% and $0.7 \%$, respectively. Due to a high content of short chain fatty acid, these fats are used in the chemical industry for the manufacture of detergents and soaps (Kostik et al. 2013). The chromatographic profile of the compounds found in the samples were compared with the spectral data of those presented in the Wiley library, and exhibited high levels of similarity.

The polyunsaturated/saturated fatty acid ratio $(\mathrm{P} / \mathrm{S})$ of the $A$. murumuru fat used was 0.007 , while several studies indicate that a higher $\mathrm{P} / \mathrm{S}$ index means a reduced deposition of lipids in the body (Kang et al. 2004). According to the investigation of (Pereira et al. 2019), the lauric acid (C12:0) content was found in major proportions (47.6\%), and the P/S index was 0.04. In another species, Astrocaryum aculeatum G. Mey (Pereira Lima et al. 2017), lauric acid also represented the majority of fatty acids.

The FTIR spectra (Fig. 2) for the three esters obtained from A. murumuru revealed evidence of the formation of esters, including $\mathrm{C}-\mathrm{H}$ stretching vibration in the $2950-2853 \mathrm{~cm}^{-1}$ region for the presence of unsaturated and saturated carbons. Stretching bands $C=0$ at $1740 \mathrm{~cm}^{-1}$ are related to carbonyl group vibration, and bands characteristic of unsaturated esters were observed, such as $C-C-O$ at $1164 \mathrm{~cm}^{-1}$ (Enumo et al. 2020). Stretching vibration $C=C$ in the region of $1655-1686 \mathrm{~cm}^{-1}$ provided evidence of the presence of unsaturated carbons. $\mathrm{CH}$ asymmetric angular stretching bands were observed at 1466-1371 $\mathrm{cm}^{-1}$ and O-C-C stretching bands in the region of $1113-1111 \mathrm{~cm}^{-1}$.

Generally, the fatty acid esters acted as an emulsion stabilizer, with different degrees of stability improvement (Park and Walsh 2019). Size distribution for DLS analysis of the emulsion (FAEE-SF, FAPE$\mathrm{SF}$ and FABE-SF) from the fatty acid ester of $A$. murumuru associated with silk protein were recorded at the beginning of the experiment and every 7 days during storage (Table 2). The size of all the emulsions prepared was satisfactory (Fig. 3), and no phase separation was observed in the formulation during storage at $-4{ }^{\circ} \mathrm{C}$ for 21 days, showing that silk protein could play an important role in the stability of the lipid particles from the conjunct of fatty acid esters. Watanabe (Watanabe et al. 2018) showed that sucrose fatty acid esters with $\mathrm{HLB}=5-7$ were suitable for obtaining $\mathrm{O} / \mathrm{W}$ emulsions. In addition, the creaming phenomenon was inhibited for 30 days or more when fatty acids with a linear saturated alkyl chain with 14 or more carbon atoms were added. These findings are useful for designing stable 0/W emulsions for food and cosmetic products.

Silk fibroin/oil emulsion stability is based on a number of factors, as follows: 1) Silk fibroin is an amphiphilic polymer with large hydrophobic domains. These hydrophobic regions are interrupted by small hydrophilic spacers, and the N and C-termini of the chains are also highly hydrophilic (Lu et al. 
2015). Therefore, the amphiphilicity of the chain organization likely plays a significant in the stability of the emulsions; 2) The viscosity of the aqueous phase increases with the addition of the silk fibroin solution, which may have inhibited droplet aggregation and gravitational separation (Feng et al. 2018). This favors Brownian motion and inhibits flocculating and coalescing (Khuwijitjaru et al. 2004; Al-Sabagh et al. 2012).

However, the results of the present study revealed that the stability of the mixture depended on the fatty acid ester type present in the sample. For FABE-SF, the particle diameter was smaller $(215.5 \pm 1.57 \mathrm{~nm}$ and $217.5 \pm 0.85$ at 0 days and the 21 st day, respectively) than the particle size of emulsions formed from fatty acid esters with propanol and ethanol $[274.06 \pm 2.41 \mathrm{~nm}$ (0 days) and $702.5 \pm 92.43 \mathrm{~nm}$ (0 days), respectively] (Table 2). Alcohols, like ethanol, induce fibroin to transform into a Silk II crystalline (Tsukada et al. 1995). However, a decay in the particle size was observed, significantly for the FAEE-SF emulsion, starting at 702.5 ( \pm 92.43$) \mathrm{nm}$ (0 day) and reducing to $229.4( \pm 8.31) \mathrm{nm}(21$ st day). It is therefore believed that the relationship between the ester structures can influence the particle diameter in the case of an emulsion formed by ethanol, propanol, and butanol fatty acid esters from $A$. murumuru fat (fatty acid mixture).

The present study showed that silk fibroin which could play an important role in the stability of the lipid particles from the conjunct of the fatty acid esters. The polydispersity index (PDI) indicates the homogeneity and stability of the size of the droplets distributed in the emulsions. According to (Lemarchand et al. 2003), PDI values of around 0.3 or below indicate the more homogeneous size distribution of the particles dispersed in the suspension. FABE-SF exhibited an excellent PDI, ranging from $0.320( \pm 0.03)$ to $0.338( \pm 0.01)$, while FAPE-SF had a PDI ranging from $0.452( \pm 0.02)$ to $0.415( \pm 0.04)$, and FAEE-SF a PDI of $0.709( \pm 0.08)$ to $0.396( \pm 0.03)$. One interesting finding was the reduction in the PDI values of the FAEE-SF and FAPE-SF nanoemulsions on the 21 st day, to 0.396 and 0.415 , respectively (Table 2). The results of this work indicate that the elongation of the ester carbon chain (-Ethyl; -Isopropyl and - $n$-Buthyl) influenced the thermodynamic balance of the phases. Factors such as the spontaneous diffusion and evaporation of volatile material from the internal phase have been observed as a mechanism for reducing droplet size (Silva et al. 2011).

Zeta potential is the electrostatic potential at the slipping plane a few molecules away from the surface (Dalgleish 1997). For the nanoemulsion to be considered stable by electrostatic repulsion alone, a zeta potential value \pm 20 is required (Honary and Zahir 2013). All nanoemulsions associated with silk protein exhibited zeta values ranging from $-53.9( \pm 4.50)$ to $-25.6( \pm 3.24) \mathrm{mV}$, during the 21 days of monitoring. It is noteworthy that FABE-SF and FAPE-SF showed greater stability throughout the entire monitoring period (Table 2). The stability of a polymer is important for the storage of a drug delivery device. The stability of these emulsions may be related to the improved balance between the dissociation of the propyl and butyl esters with the carboxylic and amino groups present in silk fibroin, resulting in a slight variation in the zeta potential for these emulsions, making them more stable. Electrophoretic mobility experiments have demonstrated that SF was positively charged below pH 3.9 and negatively charged above pH 3.9 (Malay et al. 2008), which is its pl (isoelectric point = 3.9). 
The choice of solvents of the formulation is essential for the larvicidal activity on an aqueous medium. Initially, we evaluated the effect of the fatty esters solubilized in DMSO (5\%), and the emulsions of the fatty esters associated with the silk fibroin solution, at concentrations of 25 and $75 \mu \mathrm{g} \cdot \mathrm{mL}^{-1}$ (Table 3). The results were then obtained after $24 \mathrm{~h}$ against the $A$. aegypti larva of the III instar larvae.

For at concentrations of 25 and $75 \mu \mathrm{g} \cdot \mathrm{mL}^{-1}$ tested, the results showed that all fatty acid esters (FAEE, FAPE and FABE) from $A$. murumuru fat associated with silk fibroin nanoemulsion have greater larvicidal activity against the mosquito than normal fatty acid esters in DMSO (Table 3). The FAPE-SF and FABE-SF emulsions, for example, exhibited $92 \%$ mortality at a concentration of $75 \mu \mathrm{g} \cdot \mathrm{mL}^{-1}$, while the FAEE-SF emulsion yielded a mortality rate of $68 \%$ at the same concentration. This result highlights the carrying capacity of the emulsion from fibroin and its positive impact on biological activity. It is likely that nanoemulsions associated with silk fibroin solution interact inside the larva cells, leading to a more rapid death than with the DMSO solution, due to changes in the active release kinetics (Table 4). Additionally, the hydrophobic interactions showed to be the main cause of interactions between SF and the fatty acid esters from A. murumuru fat. Similarly, previous reports by Sarquis (Sarquis et al. 2020) proposed that the nanoemulsion containing $75 \%$ silk fibroin solution (2\%), $5 \%$ fatty acid from C. guianensis Aubl. and $24 \%$ ethanol, shown be effective against $A$. aegypti (III instar larvae) with an $\mathrm{LC}_{50} 94.45 \mu \mathrm{g} \cdot \mathrm{mL}^{-1}$ at $24 \mathrm{~h}$ and $16.79 \mu \mathrm{g} \cdot \mathrm{mL}^{-1}$ at $48 \mathrm{~h}$.

One of the great advantages of silk fibroin in the emulsion system is the biodegradation process, which occurs via enzymatic degradation, the production of non-toxic by-products, and the controllable degradation rate, setting it apart from other synthetic or natural polymers (Nguyen et al. 2019).

Table 4 Here

In view of the preliminary results, other concentrations were tested to determine $\mathrm{LC}_{50}$ and $\mathrm{LC}_{90}$ at 24 and $48 \mathrm{~h}$ of nanoemulsion larvae $A$. aegypti larvae. Among the nanoemulsions in fibroin solution, FABE-SF exhibited the highest mortality percentage. After $24 \mathrm{~h}$, the mortality rate was $94 \%$ at $75 \mu \mathrm{g} \cdot \mathrm{mL}^{-1}$ and $4 \%$ at $7.5 \mu \mathrm{g} \cdot \mathrm{mL}^{-1}$, the lowest concentration tested. At $48 \mathrm{~h}$, the mortality rate was $100 \%$ at 75 and $20 \%$ at 7.5 $\mu \mathrm{g} \cdot \mathrm{mL}^{-1}$ (Fig. 4A and B). In contrast, a negative control consisting of fibroin solution only exhibited no larvicidal action. This result demonstrates the lack of toxicity of the fibroin solution towards A. aegypti.

From these results, it was also possible to establish values for the lethal concentrations $\mathrm{LC}_{50}$ and $\mathrm{LC}_{90}$ (Table 4) using Probit analysis. The fatty acid ester emulsions from murumuru oil in SF tested here exhibited good efficacy on III instar $A$. aegypti larvae, with $L_{50}$ values ranging from 29.68 to 44.56 $\mu \mathrm{g} \cdot \mathrm{mL}^{-1}$ at $24 \mathrm{~h}$, and from 18.92 to $30.29 \mu \mathrm{g} \cdot \mathrm{mL}^{-1}$ at $48 \mathrm{~h}$ (Table 4). The FAEE-SF exhibited a $\mathrm{LC}_{50}$ of $44.56 \mu \mathrm{g} \cdot \mathrm{mL}^{-1}$, while the FAPE-SF and the FABE-SF had LC ${ }_{50}$ of $40.02 \mu \mathrm{g} \cdot \mathrm{mL}^{-1}$ and $29.68 \mu \mathrm{g} \cdot \mathrm{mL}^{-1}$, respectively, at $24 \mathrm{~h}$. When the larvae of Ae. aegypti were exposed to the FAEB-SF nanoemulsion for $48 \mathrm{~h}$, the $\mathrm{LC}_{50}$ was $18.92 \mu \mathrm{g} \cdot \mathrm{mL}^{-1}$ and the $\mathrm{LC}_{90}$ was $48.51 \mu \mathrm{g} \cdot \mathrm{mL}^{-1}$. 
The present study found that around $78 \%$ of mortality was observed at a concentration lower than 75 $\mu \mathrm{g} \cdot \mathrm{mL}^{-1}$ for the FAEE-SF and FAPE-SF nanoemulsions, after $24 \mathrm{~h}$ of exposure of the larvae to nanoemulsions. The FABE-SF nanoemulsion at $24 \mathrm{~h}$ exhibited mortality of $92 \%$ at a concentration of 75 $\mu \mathrm{g} \cdot \mathrm{mL}^{-1}$, and $100 \%$ mortality after $48 \mathrm{~h}$. These results make it clear that emulsions of different esters with silk fibroin represent promising larvicidal agents against Ae. aegypti.

Although the toxicity mechanism of these nanoemulsions is not very well known, we suggest that the larvicidal properties of nanoemulsions, especially FABE-SF, come from its hydrophobic character/interaction with the silk protein, enhanced by the increase in the alkyl grease chain.

A set of methyl esters, from long saturated chains, extracted from the leaves of Vitex trifolia, exhibited good larvicidal activity against the $C$. quinquefasciatus mosquito, exhibiting $\mathrm{LC}_{50}$ and $\mathrm{LC}_{90}$ values of 9.26 and $21.28 \mu \mathrm{g} \cdot \mathrm{mL}^{-1}$, respectively, after $24 \mathrm{~h}$ treatment. It should be stated that this species had a high composition of lauric acid (Kannathasan et al. 2008).

De Melo (De Melo et al. 2018) evaluated the larvicidal action of oleic, linoleic, linolenic, palmitic and stearic acids, as well as their respective methyl esters, against the larvae of $C$. quinquefasciatus, and found that the oleic, linoleic and linolenic acid exhibited values of $\mathrm{CL}_{50}$ of $8.58,10.04$, and $19.78 \mu \mathrm{g} \cdot \mathrm{mL}^{-}$ 1 , respectively, after $24 \mathrm{~h}$.

Methyl esters from canola, corn, sunflower and soybean oils show LC $_{50}$ values varying 42.32 to 196.27 $\mu \mathrm{g} \cdot \mathrm{mL}^{-1}$, against the larvae of $3 \mathrm{rd}$ and 4 th $C$. quinquefasciatus after $144 \mathrm{~h}$ of exposure. The lowest $\mathrm{CL}_{50}$ value was observed for the soybean oil methyl ester (42.32 $\left.\mu \mathrm{g} \cdot \mathrm{mL}^{-1}\right)$ (Ribeiro-Neto et al. 2017).

However, it should be mentioned that most research with emulsions, nanoemulsions or solutions, even when obtained from plant extracts, use solvents or emulsifiers of significant toxicity, which can interfere with biological processes or cell maintenance.

Toxicity is therefore an important factor in the choice of surfactants, which are potentially irritating or poorly tolerated, as they have nonspecific effects on biological membranes. In general, cationic surfactants are more toxic than anionic surfactants, which in turn are more toxic than nonionic surfactants (Pouton and Porter 2008). In view of the above, silk protein represents a highly viable alternative in the use of these surfactants, as it is a biomaterial that does not exhibit cellular toxicity (Fig. 5).

The effects of FABE-SF and the solution of $A$. murumuru fat in silk fibroin were evaluated on erythrocytes isolated of the blood from rats in function of incubation time $(1 \mathrm{~h})$ at the following concentrations $(5,10$, 25, 50 and $75 \mu \mathrm{g} \cdot \mathrm{mL}^{-1}$ ). The FABE-SF emulsion was chosen for the hemolysis test as it exhibited better larvicidal activity results.

The hemolysis percentage results are shown in Fig. 5. Both the emulsion and the fat solution of $A$. murumuru in silk fibroin exhibited a low capacity for hemolysis at the tested concentrations, of less than 
$6 \%$ even at the highest concentration $\left(75 \mu \mathrm{g} \cdot \mathrm{mL}^{-1}\right)$, compared with the $0,1 \%$ Triton $\mathrm{X}-100$ solution (positive control). The silk fibroin solution used as a negative control did not exhibit erythrocyte lysis, suggesting excellent biocompatibility, behaving like a highly sustainable emulsion. Amino acid-based surfactants have the ability to interact with the lipid bilayer of cell membranes. The action of five amino acids derived from anionic lysine type $N^{a}, N^{\varepsilon}$ - dioctanoyl lysine and three cationic surfactants derived from arginine (methyl ester of $N^{a}$ - lauroyl-L-arginine, methyl ester of $N^{a}$ - myristoyl -L- arginine and derivatives of methyl $N^{a}$-acyl-arginine), both surfactants, exhibited strong anti-hemolysis action (Sánchez et al. 2007).

The action of surfactants based on amino acids in plasma membranes is complex. A possible relationship between these surfactants, and their effects on the cell membrane may be due to the amphiphilic character of these surfactants, since they are interspersed in the lipid bilayer of the membrane. So the hydrophilic region is located at the hydrophilic/hydrophobic interface of the membrane and the hydrophobic region in the core of the bilayer (Zachowski and Durand 1988).

The results of the present study also suggest that there is no interaction between the FABE-SF nanoemulsion and erythrocytes, since the presence of silk fibroin in the negative control did not cause cell lysis. Silk fibroin, as well as surfactants based on amino acids, has an amphiphilic character; in addition, repulsion forces can occur between the negative surface charge of the silk fibroin and the negative charges present in the erythrocyte membranes.

Optical microscopy images of $A$. aegypti larvae after $48 \mathrm{~h}$ of exposure in the nanoemulsions (FAEE-SF, FAPE-SF and FABE-SF) revealed particles of the emulsions precipitated in the larvae, which causes lesions in the cuticles of the initial segment of the larvae, such as the head and thorax. In addition to adhering to its lateral bristles, while darkening and torsion in the larvae body was also observed (Fig. 6a). The morphological damage in the larvae is the lethality effect of the nanoemulsions. Sarquis (Sarquis et al. 2020) observed similar changes when using a nanoemulsion with free fatty acid from $C$. guianensis and silk fibroin, which was able to cause changes in the anal papilla and in the digestive and respiratory systems of $A$. aegypti larvae. Araújo (Araújo et al. 2020) observed morphological damage in the respiratory siphon and anal papilla in $A$. aegypti larvae when using hexanic extract from the leaves of Acmella oleracea solubilized in silk fibroin. There were no changes in the structures of the larvae exposed to the control (Fig. 6b).

It FABE-SF nanoemulsion is based on global trends towards sustainable development stimulate the use of renewable and biodegradable raw materials, as esters of murumuru, with higher biological performance in comparison to a synthetic-based vehicle, this case DMSO, to mosquito larval control, based drug delivery system.

\section{Conclusion}


This is the first study to use different esters associated with silk fibroin as larvicidal agents. The esters (FAEE, FAPE and FABE) associated with the silk fibrin solution exhibited strong larvicidal activity, especially the FABE-SF nanoemulsion, which exhibited $\mathrm{C} \mathrm{CL}_{50}$ value of $18.92 \mu \mathrm{g} \cdot \mathrm{mL}^{-1}$, after $48 \mathrm{~h}$ of larvae exposure. It displayed greater temporal stability throughout all 21 days of monitoring, with an average particle value of $217( \pm 0.85) \mathrm{nm}$, zeta potential of $-25.6( \pm 3.24) \mathrm{mV}$ and a PDI of $0.338( \pm 0.01)$. The FABE-SF exhibit both a hydrophobic and hydrophilic character, increasing the biodistribution and bioavailability controlled of the fatty acid esters in the aqueous medium. It also observed that the nanoemulsions caused structural changes in the larvae, affecting their development and survival. This mortality rate shows that the formulations can be used as biopesticides.

\section{Declarations}

\section{CRediT authorship contribution statement}

Victor H. Marinho, Fernando B. Neves and Fábio R. Oliveira: Conceptualization, Methodology, Validation, Software, Formal analysis, Investigation, Data curation, Writing - original draft. Sergio A. Yoshioka, Ricardo M. A. Ferreira, David E. J. Quintero, Abraão V. T. L. Santos: Methodology, Investigation, Writing original draft, Writing - review \& editing, Visualization. Irlon M. Ferreira, Raimundo N. P. Souto and José C. T. Carvalho: Conceptualization, Methodology, Resources, Writing - review \& editing, Supervision, Project administration, Funding acquisition.

\section{Ethics approval and consent to participate}

Not applicable.

\section{Consent for publication}

Not applicable.

\section{Availability of data material}

All data generated or analysed during this study are included in this published article (and its additional files).

\section{Declaration of Competing Interest}

The authors declare that they have no known competing financial interests or personal relationships that could have appeared to influence the study reported in this paper.

\section{Acknowledgements}

The authors would like to acknowledge the Research Support Foundation of the State of Amapá (Fundação de Amparo à Pesquisa do Estado do Amapá, FAPEAP; grant no. 34568.515.22257.28052017). The Coordination for the Improvement of Higher Education Personnel - Brazil (CAPES), by the financing in 
part of the present work and to Graduate Program in Biodiversity and Biotechnology of the BIONORTE Network (PPG-BIONORTE) for their financial support.

\section{References}

Al-Sabagh AM, Emara MM, Noor El-Din MR, Aly WR (2012) Preparation of water-in-diesel fuel nanoemulsions using high-energy emulsification method and a study of some of their surface active properties. J Dispers Sci Technol 33:970-976. https://doi.org/10.1080/01932691.2011.590426

Araújo IF, Loureiro HA, Marinho VHS, et al (2020) Larvicidal activity of the methanolic, hydroethanolic and hexanic extracts from Acmella oleracea, solubilized with silk fibroin, against Aedes aegypti. Biocatal Agric Biotechnol 24:101550. https://doi.org/10.1016/j.bcab.2020.101550

Baldacchino F, Caputo B, Chandre F, et al (2015) Control methods against invasive Aedes mosquitoes in Europe: A review. Pest Manag Sci 71:1471-1485. https://doi.org/10.1002/ps.4044

Benelli G, Mehlhorn H (2016) Declining malaria, rising of dengue and zika virus: insights for mosquito vector control. Parasitol Res 115:1747-1754. https://doi.org/10.1007/s00436-016-4971-z

Bezerra VS (2012) Considerações sobre a palmeira murumuruzeiro (Astrocaryum murumuru Mart.). Comun Técnico, 130 1-6 (in Portuguese).

Bosch OJ, Geier M, Boeckh J (2000) Contribution of fatty acids to olfactory host finding of female Aedes aegypti. Chem Senses 25:323-330. https://doi.org/10.1093/oxfordjournals.chemse.a014042

Cheng Q, Zhang B, He Y, et al (2017) Silk nanofibers as robust and versatile emulsifiers. ACS Appl Mater Interfaces 9:35693-35700. https://doi.org/10.1021/acsami.7b13460.

Dalgleish DG (1997) Adsorption of protein and the stability of emulsions. Trends Food Sci Technol 8:1-6. https://doi.org/10.1016/S0924-2244(97)01001-7

De Melo AR, Pereira Garcia IJ, Serrão JE, et al (2018) Toxicity of different fatty acids and methyl esters on Culex quinquefasciatus larvae. Ecotoxicol Environ Saf 154:1-5.

https://doi.org/10.1016/j.ecoenv.2018.02.009

Echeverría J, Albuquerque R (2019) Nanoemulsions of essential oils: New tool for control of vector-borne diseases and in vitro effects on some parasitic agents. Medicines 6:42.

https://doi.org/10.3390/medicines6020042

Enumo A, Gross IP, Saatkamp RH, et al (2020) Evaluation of mechanical, thermal and morphological properties of PLA films plasticized with maleic acid and its propyl ester derivatives. Polym Test 88:106552. https://doi.org/10.1016/j.polymertesting.2020.106552 
Erdemoglu N, Kusmenoglu S (2003) Fatty acid composition of Zygophyllum fabago seeds. Khimiya Prir Soedin 2003:492-493.

Feng J, Chen Q, Wu X, et al (2018) Formulation of oil-in-water emulsions for pesticide applications: impact of surfactant type and concentration on physical stability. Environ Sci Pollut Res 25:2174221751. https://doi.org/10.1007/s11356-018-2183-z

Ferreira IM, Coutinho L, Akinobo S, et al (2014) Chemoselective reduction of chalcones by whole hyphae of marine fungus Penicillium citrinum CBMAI 1186, free and immobilized on biopolymers. Biocatal Agric Biotechnol 1-7. https://doi.org/10.1016/j.bcab.2014.04.001

Ferreira IM, Ganzeli LDS, Rosset IG, Yoshioka SA (2017a) Ethylic Biodiesel Production Using Lipase Immobilized in Silk Fibroin-Alginate Spheres by Encapsulation. Catal Letters 147:269-280. https://doi.org/10.1007/s10562-016-1917-0

Ferreira IM, Yoshioka SA, Comasseto J V., Porto ALM (2017b) Immobilization of Amano lipase from Pseudomonas fluorescens on silk fibroin spheres: an alternative protocol for the enantioselective synthesis of halohydrins. RSC Adv 7:12650-12658. https://doi.org/10.1039/c7ra00083a

Gilliom RJ, Hamilton PA (2006) Pesticides in the nation's streams and groundwater, 1992-2001: a summary. United States Geol Surv Fact Sheet 2006-3028.

Honary S, Zahir F (2013) Effect of Zeta Potential on the Properties of Nano-Drug Delivery Systems - A Review ( Part 2 ). 12:265-273.

Kaci M, Arab-Tehrany E, Desjardins I, et al (2017) Emulsifier free emulsion: comparative study between a new high frequency ultrasound process and standard emulsification processes. J Food Eng 194:109118. https://doi.org/10.1016/j.jfoodeng.2016.09.006

Kang C, Munawir A, Cha M, et al (2009) Cytotoxicity and hemolytic activity of jelly fish Nemopilema nomurai ( Scyphozoa: Rhizostomeae ) venom. Comp Biochem Physiol Part C 150:85-90.

https://doi.org/10.1016/j.cbpc.2009.03.003

Kang MJ, Lee EK, Lee SS (2004) Effects of two P/S ratios with same peroxidizability index value and antioxidants supplementation on serum lipid concentration and hepatic enzyme activities of rats. Clin Chim Acta 350:79-87. https://doi.org/10.1016/j.cccn.2004.07.005

Kannathasan K, Senthilkumar A, Venkatesalu V, Chandrasekaran M (2008) Larvicidal activity of fatty acid methyl esters of Vitex species against Culex quinquefasciatus. Parasitol Res 103:999-1001.

https://doi.org/10.1007/s00436-008-1078-1 
Khuwijitjaru P, Kimura Y, Matsuno R, Adachi S (2004) Preparation of finely dispersed O/W emulsion from fatty acid solubilized in subcritical water. J Colloid Interface Sci 278:192-197.

https://doi.org/10.1016/j.jcis.2004.05.032

Koh LD, Cheng Y, Teng CP, et al (2015) Structures, mechanical properties and applications of silk fibroin materials. Prog Polym Sci 46:86-110.

https://doi.org/10.1016/j.progpolymsci.2015.02.001

Korul'kina LM, Zhusupova GE, Shul'ts EE, Erzhanov KB (2004) Fatty-acid composition of two Limonium plant species. Chem Nat Compd 40:417-419. https://doi.org/10.1007/s10600-005-0002-5

Kostik V, Memeti S, Bauer B (2013) Fatty acid composition of edible oils and fats. J Hyg Eng Des 4:112116.

Kundu J, Chung Y II, Kim YH, et al (2010) Silk fibroin nanoparticles for cellular uptake and control release. Int J Pharm 388:242-250. https://doi.org/10.1016/j.ijpharm.2009.12.052

Lemarchand C, Couvreur P, Vauthier C, et al (2003) Study of emulsion stabilization by graft copolymers using the optical analyzer Turbiscan. Int J Pharm 254:77-82. https://doi.org/10.1016/S03785173(02)00687-7

Lu S, Li J, Zhang S, et al (2015) The influence of the hydrophilic-lipophilic environment on the structure of silk fibroin protein. J Mater Chem B 3:2599-2606. https://doi.org/10.1039/c4tb01873g

Malay Ö, Yal DÏ, Bat AÏ, Bayraktar O (2008) Characterization of silk fibroin/hyaluronic acid polyelectrolyte complex (PEC) films. https://doi.org/10.1007/s10973-008-9368-5

Nguyen TP, Nguyen QV, Nguyen V, et al (2019) Silk Fibroin-Based Biomaterials for Biomedical. 1-25.

Noufi R (1995) L 0 1995. 3:235-238.

Park N, Walsh MK (2019) Physical and emulsion stabilizing properties of maltodextrin fatty acid polymers produced by lipase-catalyzed reactions in ethanol. Carbohydr Polym 226:115309.

https://doi.org/10.1016/j.carbpol.2019.115309

Pereira E, Ferreira MC, Sampaio KA, et al (2019) Physical properties of Amazonian fats and oils and their blends. Food Chem. 278:208-215.

Pereira Lima R, Souza da Luz PT, Braga M, et al (2017) Murumuru (Astrocaryum murumuru Mart.) butter and oils of buriti (Mauritia flexuosa Mart.) and pracaxi (Pentaclethra macroloba (Willd.) Kuntze) can be used for biodiesel production: Physico-chemical properties and thermal and kinetic studies. Ind Crops Prod 97:536-544. https://doi.org/10.1016/j.indcrop.2016.12.052 
Perumalsamy H, Jang MJ, Kim JR, et al (2015) Larvicidal activity and possible mode of action of four flavonoids and two fatty acids identified in Millettia pinnata seed toward three mosquito species.

Parasites and Vectors 8:1-14. https://doi.org/10.1186/s13071-015-0848-8

Pham DT, Tiyaboonchai W (2020) Fibroin nanoparticles: a promising drug delivery system. Drug Deliv 27:431-448. https://doi.org/10.1080/10717544.2020.1736208

Pouton CW, Porter CJH (2008) Formulation of lipid-based delivery systems for oral administration: Materials, methods and strategies. Adv Drug Deliv Rev 60:625-637.

https://doi.org/10.1016/j.addr.2007.10.010

Ribeiro-Neto JA, Pinto MEA, Ferreira VV., et al (2017) Larvicidal activity of vegetable oils and esterified compounds against Culex quinquefasciatus (Diptera: Culicidae). Ecotoxicol Environ Saf 143:57-61. https://doi.org/10.1016/j.ecoenv.2017.05.004

Rodrigues AM, Sampaio C de G, de Souza JSN, et al (2019) Different susceptibilities of Aedes aegypti and Aedes albopictus larvae to plant-derived products. Rev Soc Bras Med Trop 52:0-2.

https://doi.org/10.1590/0037-8682-0197-2018

Sánchez L, Martínez V, Rosa Infante M, et al (2007) Hemolysis and antihemolysis induced by amino acidbased surfactants. Toxicol Lett 169:177-184. https://doi.org/10.1016/j.toxlet.2007.01.003

Sarquis IR, Marinho VHS, Neves FB, et al (2020) Industrial Crops \& Products Carapa guianensis Aubl. (Meliaceae) oil associated with silk fibroin, as alternative to traditional surfactants, and active against larvae of the vector Aedes aegypti. 157. https://doi.org/10.1016/j.indcrop.2020.112931

Sarwar M, Ahmad N, Toufiq M (2009) Host plant resistance relationshiphs in chickpea (Cicer arietinum L.) against gram pod borer (Helicoverpa armigera Hubner). Pakistan J Bot 41:3047-3052.

Sharma P, Mohan L, Dua KK, Srivastava CN (2011) Status of carbohydrate, protein and lipid profile in the mosquito larvae treated with certain phytoextracts. Asian Pac J Trop Med 4:301-304. https://doi.org/10.1016/S1995-7645(11)60090-4

Sharma P, Mohan L, Srivastava CN (2009) Amaranthus oleracea and Euphorbia hirta: Natural potential larvicidal agents against the urban Indian malaria vector, Anopheles stephensi Liston (Diptera: Culicidae). Parasitol Res 106:171-176. https://doi.org/10.1007/s00436-009-1644-1

Silva HD, Cerqueira MA, Souza BWS, et al (2011) Nanoemulsions of $\beta$-carotene using a high-energy emulsification- evaporation technique. J Food Eng 102:130-135.

https://doi.org/10.1016/j.jfoodeng.2010.08.005 
Suarez PAZ, Plentz Meneghetti SM, Meneghetti MR, Wolf CR (2007) Transformation of triglycerides into fuels, polymers and chemicals: Some applications of catalysis in oleochemistry. Quim Nova 30:667-676. https://doi.org/10.1590/s0100-40422007000300028

Tanaka K, Inoue S, Mizuno S (1999) Hydrophobic interaction of P25, containing Asn-linked oligosaccharide chains, with the H-L complex of silk fibroin produced by Bombyx mori. Insect Biochem Mol Biol 29:269-276. https://doi.org/10.1016/S0965-1748(98)00135-0

Tsukada M, Freddi G, Monti P, et al (1995) Structure and molecular conformation of tussah silk fibroin films: Effect of methanol. J Polym Sci Part B Polym Phys 33:1995-2001.

https://doi.org/10.1002/polb.1995.090331402

Watanabe T, Kawai T, Nonomura Y (2018) Effects of fatty acid addition to oil-in-water emulsions stabilized with sucrose fatty acid ester. J Oleo Sci 67:307-313. https://doi.org/10.5650/jos.ess17097

Zachowski A, Durand P (1988) Biphasic nature of the binding of cationic amphipaths with artificial and biological membranes. BBA - Biomembr 937:411-416. https://doi.org/10.1016/0005-2736(88)90263-5

Zhang YQ, Shen W De, Xiang RL, et al (2007) Formation of silk fibroin nanoparticles in water-miscible organic solvent and their characterization. J Nanoparticle Res 9:885-900.

https://doi.org/10.1007/s11051-006-9162-x

\section{Tables}

Tables 1-4 are available in the Supplementary Information.

\section{Figures}




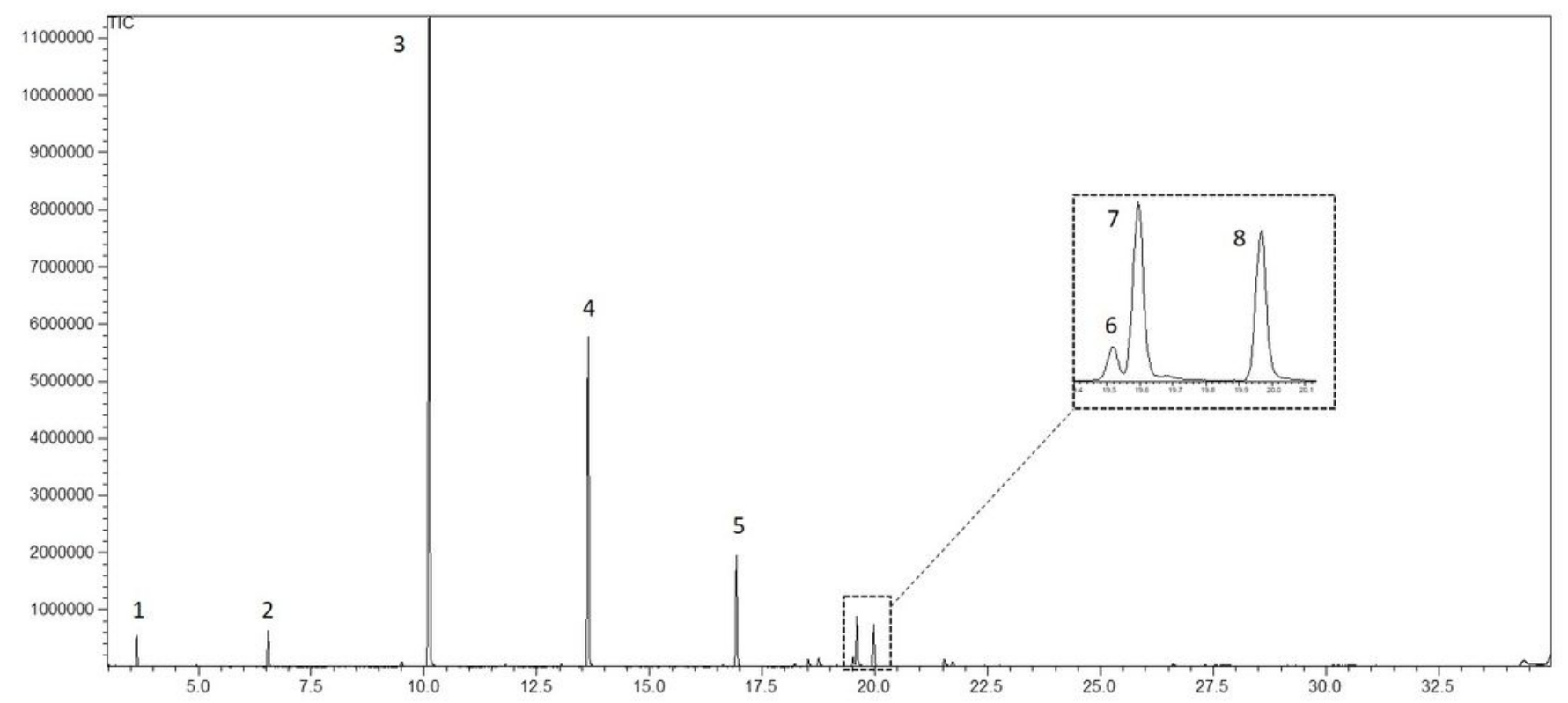

Figure 1

Note: a figure caption was not provided in this version.

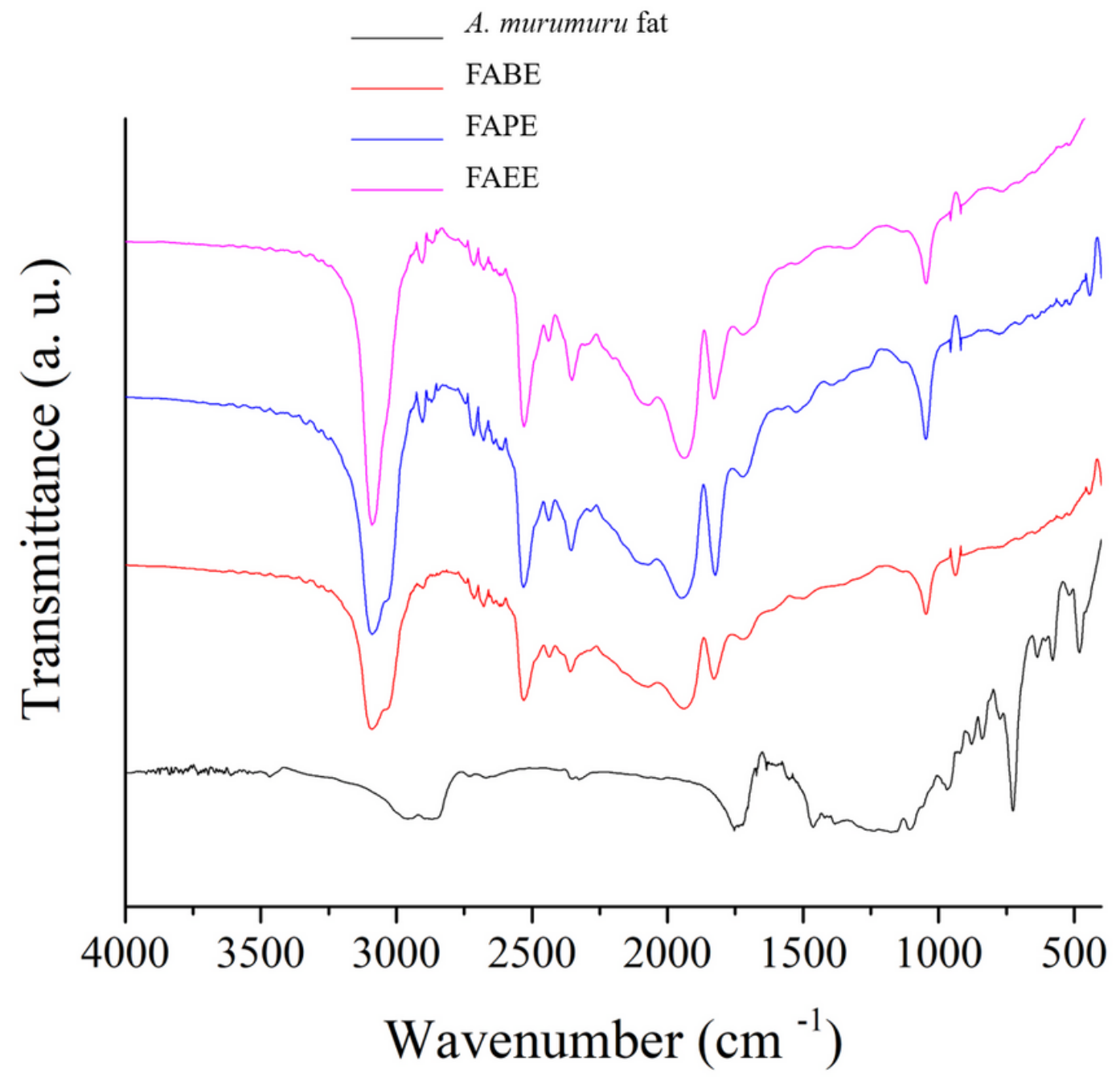

Page $19 / 22$ 
Figure 2

Note: a figure caption was not provided in this version.

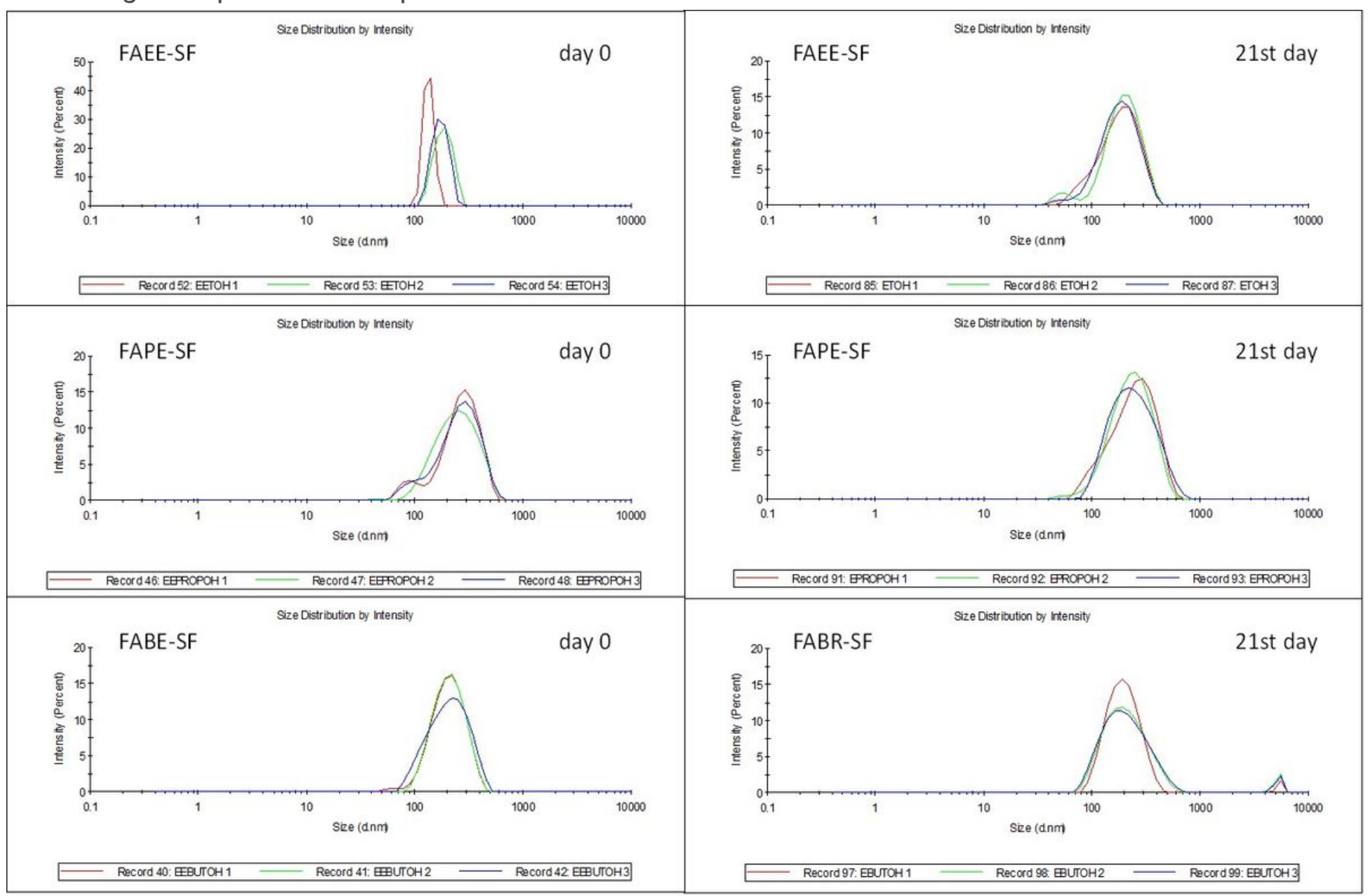

Figure 3

Note: a figure caption was not provided in this version. 


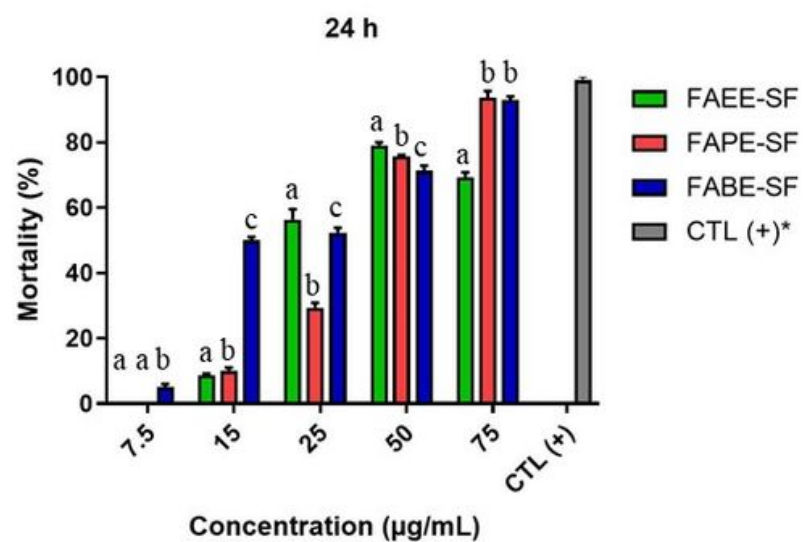

(a)

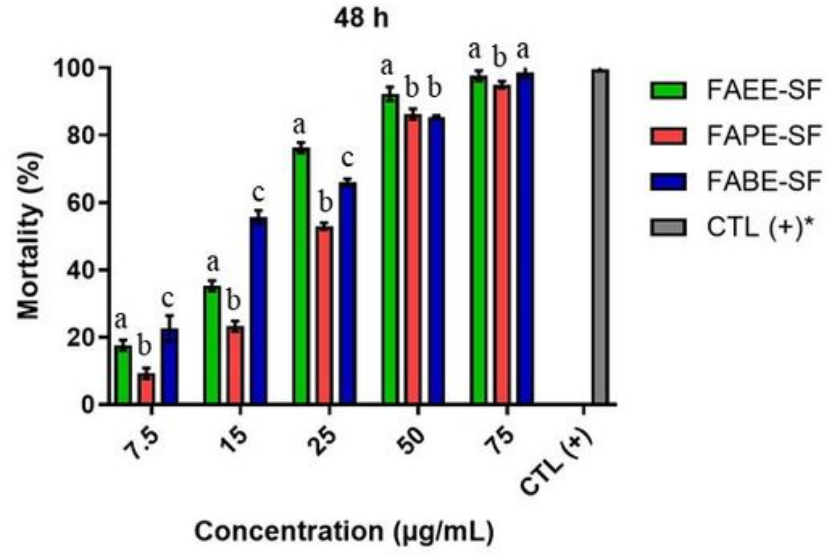

(b)

\section{Figure 4}

Note: a figure caption was not provided in this version.

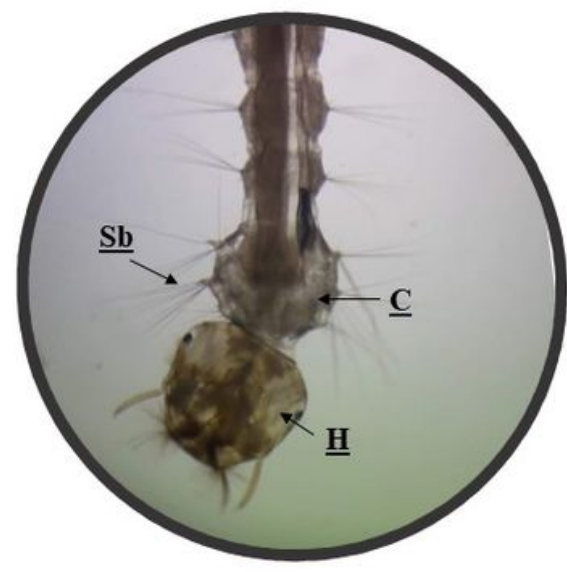

(a)

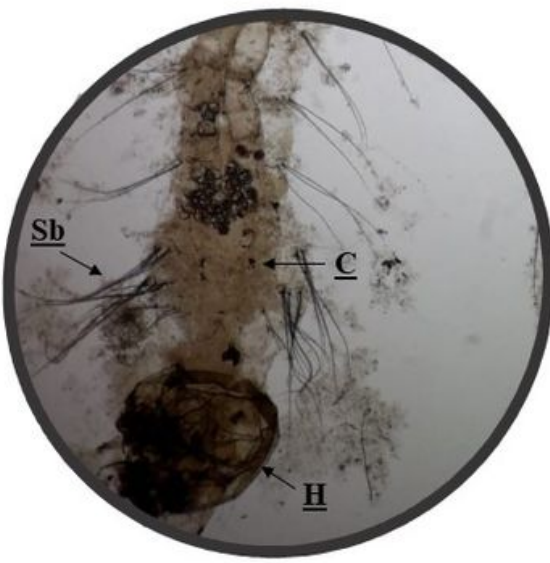

(b) 
Figure 5

Note: a figure caption was not provided in this version.

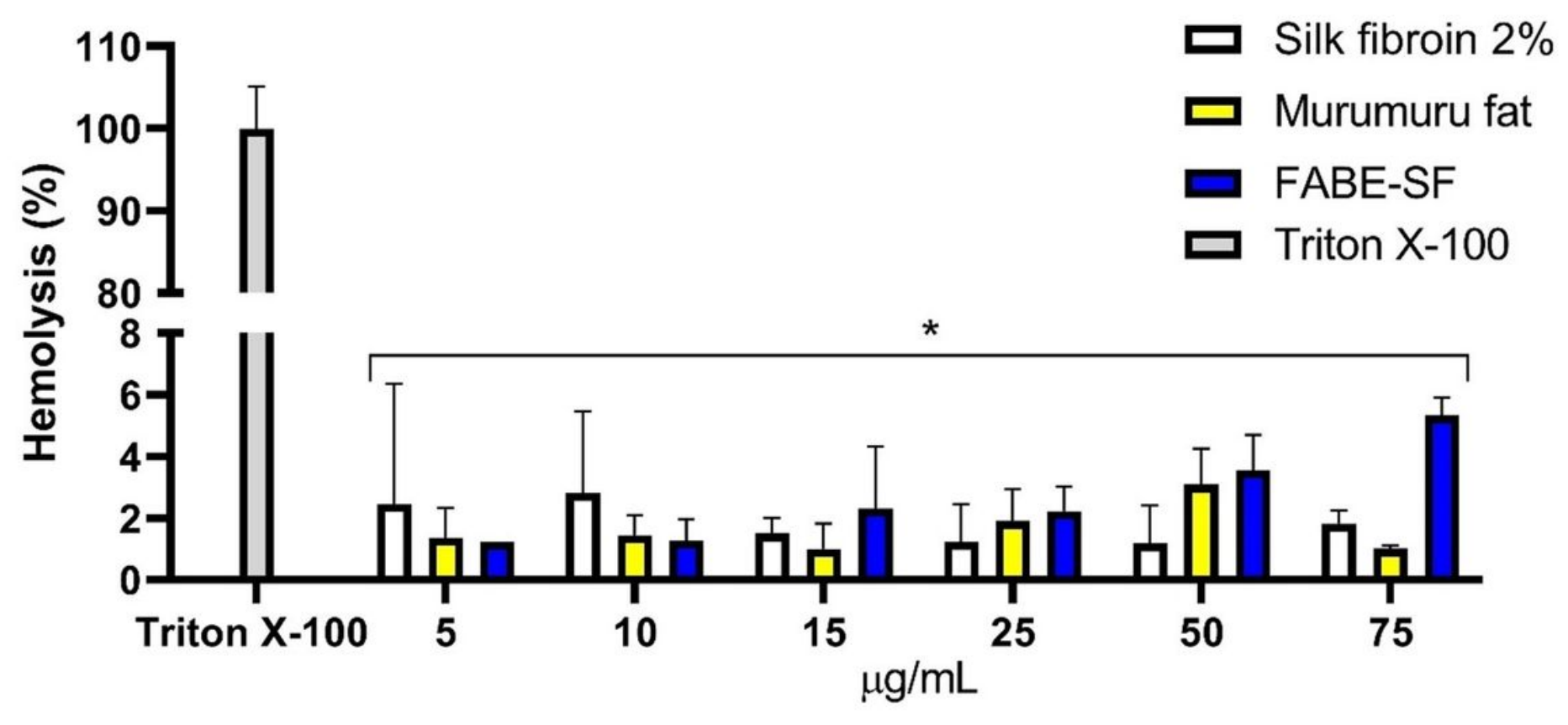

Figure 6

Note: a figure caption was not provided in this version.

\section{Supplementary Files}

This is a list of supplementary files associated with this preprint. Click to download.

- Graphic.jpg

- Table1.docx

- Table2.docx

- Table31.docx

- Table41.docx

- SupplementaryInformationvitor.docx 